УДК 57.084 .1

doi: $10.31140 / j . v e s t n i k i b .2016 .3(197) .3$

\title{
ОСНОВНЫЕ ПРИНЦИПЫ НАДЛЕЖАЩЕЙ ЛАБОРАТОРНОЙ ПРАКТИКИ (НЛП, GLP) ПРИ ОБУСТРОЙСТВЕ ВИВАРИЯ И ОРГАНИЗАЦИИ НАУЧНЫХ ИССЛЕДОВАНИЙ
}

\author{
О.В. Раскоша' ${ }^{1,2}$, А.И. Кичигин ${ }^{1}$ \\ 1 Федеральное государственное бюджетное учреждение науки \\ Институт биологии Коми научного центра Уральского отделения РАН, Сыктывкар \\ ${ }^{2}$ Сыктывкарский государственный университет им. П. Сорокина, Сыктывкар \\ E-mail: raskosha@ib.komusc.ru
}

\begin{abstract}
Аннотация. В статье рассмотрены основные требования GLP (Good Laboratory Practice) к обустройству и проектированию вивариев, содержанию животных, а также к организации работы испытательных центров.
\end{abstract}

Ключевые слова: принципы надлежащей лабораторной практики, GLP, обустройство вивариев, требования к содержанию животных, испытательный центр, научные исследования

Принципы надлежащей лабораторной практики (Good Laboratory Practice, GLP) - это международная система правил и требований к лабораториям, которые занимаются изучением воздействия новых химических веществ на окружающую среду и здоровье человека (ГОСТ 330442014). Главная цель GLP состоит в том, чтобы обеспечить получение надежных результатов путем реализации системы качества организационного процесса и условий, при которых планируются, проводятся и контролируются неклинические исследования безопасности продукта, документируются и архивируются данные и составляются отчеты (Добротная..., 2009).

В настоящее время эти правила и требования применяются во многих странах мира как обязательный стандарт качества при проведении доклинических исследований, что позволяет обеспечить стандартизацию исследований и взаимное признание полученных результатов. Начало этому было положено в 1976 г., когда агентство по лекарствам и пищевым продуктам Министерства здравоохранения и социальных служб США (Food and Drug Administration, FDA или USFDA) предложило разработать единые правила надлежащей лабораторной практики. Поводом послужила серия скандалов, связанных с фальсификацией результатов лабораторных испытаний фармакологическими компаниями. Уже в 1979 г. GLP стала обязательным требованием для фармацевтических лабораторий на территории США. В 1981 г. Организация экономического сотрудничества и развития (ОЭСР, Organisation for Economic Cooperation and Development, OECD) также сформулировала международные принципы $G L P$, выполнение которых является обязательным для лабораторий всех стран-участниц этой организации. Таким образом, на сегодняшний день существуют две основные системы GLP, незначительно отличающиеся друг от друга - принятая в США система GLP FDA и система GLP OECD. Боль- шинство центров, осуществляющих неклинические исследования в соответствии с принципами $G L P$, находится в США (около 200 коммерческих и более 50 университетских центров (лабораторий).

В последние годы и перед Россией встала задача приведения лабораторий к международным стандартам, в частности, к стандартам GLP таким было одно из условий присоединения нашей страны к ОЭСР. В 2010 г. опубликован ГОСТ 53434-2009 «Принципы надлежащей лабораторной практики», который предназначен «для применения при проведении неклинических испытаний объектов, содержащихся в лекарственных средствах, пестицидах, косметической продукции, ветеринарных препаратах, пищевых и кормовых добавках, а также химических веществ промышленного назначения». Согласно этим принципам, цель испытаний состоит в том, чтобы получить надежные и воспроизводимые данные о свойствах испытуемых объектов и/или о их безопасности для здоровья людей и/или окружающей среды. В этом же году опубликовано первое российское руководство, содержащее гармонизированные с международными стандартами требования к использованию в неклинических исследованиях качественных животных и валидированных альтернативных моделей (Руководство..., 2010). В декабpe 2012 г. вышло распоряжение Правительства Российской Федерации «Об утверждении Национальной программы реализации принципов надлежащей лабораторной практики ОЭСР в деятельности российских испытательных центров (лабораторий) в области неклинических лабораторных исследований». Годом позже официальным органом по мониторингу лабораторий и подготовке инспекторов была объявлена Федеральная служба по аккредитации ( Росаккредитация»), утвержден ряд ГОСТов (ГОСТ 31881-2012-ГОСТ 31891 2012), которые являются переводами соответствующих документов ОЭСР. Несмотря на то, что в 
2014 г. процесс вступления Российской Федерации в ОЭСР приостановлен, деятельность по стандартизации лабораторий по требованиям GLP продолжает развиваться. С 1 августа 2015 г. введен в действие в качестве национального стандарта Российской Федерации ГОСТ 33044-2014 «Принципы надлежащей лабораторной практики», в котором в отличие от предыдущего (ГОСТ 534342009) приводятся пояснения для пользователей в части назначения и применения принципов GLP.

На сегодняшний день в России нет обязательного требования по проведению доклинических исследований именно в лабораториях, аккредитованных по стандартам $G L P$, однако, реализуется курс на то, чтобы как можно больше лабораторий имели этот статус. Одной из первых в России сертификат $G L P$ получила лаборатория биологических испытаний (ФГБУН Институт биоорганической химии им. академиков М.M. Шемякина и Ю.А. Овчинникова РАН). Руководитель этой лаборатории А. Мурашев считает, что исследования можно качественно выполнять и не по стандарту $G L P$, но если они выполнены по стандарту, то потенциально результаты могут принима'ьь во всех странах ОЭСР, а это реальный выход на международный рынок (Курская, 2014).

Проанализировав доступную нам литературу по этой теме и приняв участие в работе семинара «Доклинические исследования. Современные тенденции и проблемы. GLP в виварии», который проводила фирма ООО «Фармбиолайн» (30 марта 2016, г. Москва), мы также пришли к заключению, что при создании современного вивария, а с учетом исследований, которые планируется проводить на его базе, то и в целом испытательного центра, необходимо руководствоваться основными принципами лабораторной практики, основанными на международных стандартах. В данной статье представлены некоторые требования к обустройству вивария и организации исследовательской работы по принципам $G L P$. Следует отметить, что это лишь попытка разобраться в многообразии правил, норм и методических указаний, которые необходимо соблюдать в случае, если виварий претендует на соответствие этим стандартам. Ряд не менее важных вопросов остался за рамками этой публикации, некоторые из них освещены в статьях и книгах, авторами которых пройден сложный путь становления и обустройства $G L P$-лабораторий, в состав которых входят виварии или питомники (Murashev, 2006; Мошкин, 2008).

Согласно Руководству по лабораторным животным и альтернативным моделям в биомедицинских исследованиях (Руководство..., 2010), правила $G L P$ определяют технологию проведения доклинических испытаний, связанных с опреде- лением безопасности исследуемого вещества, и включают в себя:

- требования к организации испытаний;

- требования к личному составу исследователей;

- требования к помещениям, в которых проводятся испытания и содержатся животные;

- требования к качеству животных, условиям их содержания и кормления;

- требования к лабораторному оборудованию и к его калибровке;

- требования к испытуемому и контрольному веществу;

- требования к составлению и проведению подробной стандартной методики экспериментальных работ (стандартные операционные процедуры, СОП) и к порядку проведения испытаний (протокол);

- требования к регистрации данных и оформлению отчета;

- требования к службе контроля за качеством испытаний;

- стандартные методики экспериментальных работ.

Требования к размещению, проектированию и оборудованию вивариев. Одним из основных требований $G L P$, предъявляемым к экспериментально-биологическим лабораториям (вивариям), является правильное содержание, использование и гуманное обращение с животными (Хамидулина, 2012). Поэтому при содержании животных необходимо соблюдать требования к размещению, проектированию и оборудованию вивариев, приему и содержанию животных с учетом санитарно-гигиенических и биоэтических аспектов работы с лабораторными животными.

В соответствии с требованием СП 2.2.1.321814 , при размещении вивария в лабораторном корпусе организации помещения вивария изолируют от помещений иного назначения, в том числе административных и бытовых помещений организации. Виварий оборудуют отдельным входом и автономными системами вентиляции. При размещении вивария на верхних этажах здания организации оборудуют отдельный лифт или отдельную лестницу. Важным является то, что при планировке и размещении помещений вивария обеспечивают соблюдение принципа разделения площадей на «чистые» и «грязные» помещения и предусматривают условия, исключающие встречные или перекрестные потоки перемещений оборудования, инвентаря, материалов, персонала вивария, лабораторных животных с различной степенью эпидемиологической опасности из «грязных» в «чистые» помещения. В составе «чистых» помещений предусматривают:

- помещения приема, карантина и адаптации вновь поступающих животных;

- помещения экспериментальных животных; 
- операционную с предоперационной для экспериментальных работ, требующих особых условий;

- помещения хранения чистого (обеззараженного) инвентаря для ухода за животными (клеток, поилок, посуды для кормов, оборудования);

- помещение манипуляционной для изучения обменных процессов, взятия проб для анализа;

- помещения для хранения и приготовления кормов для животных;

- диагностический кабинет;

- помещение или оборудованная выделенная зона для испытуемых образцов (биологические материалы) и образцов сравнения.

В составе «грязных» помещений предусматривают:

- помещения изоляторов, предназначенные для содержания подозрительных по инфекционным заболеваниям животных или больных животных;

- помещение (или отделение) для мойки и дезинфекции оборудования и инвентаря;

- холодильное помещение или холодильная камера для сбора и хранения трупов животных, отходов;

- помещения для персонала вивария (душевая, туалет и гардеробная).

Помещения для содержания лабораторных животных оборудуют принудительной приточновытяжной вентиляцией, при этом устройство вентиляции должно исключать перетекание воздушных масс из «грязных» зон в «чистые» (Руководство..., 1996). В виварии обязательно наличие холодного и горячего водоснабжения с водой соответствующего качества (СанПиН 2.1.4.1074-01) и системы канализации, которая должна быть раздельной для отвода хозяйственно-бытовых стоков (от туалетов, душевых) и технологических стоков (от инженерно-технологического оборудования, трапов, моечного оборудования) (СП 2.2.1.3218-14).

Оборудование, находящееся в виварии и в целом в испытательном центре, необходимо эксплуатировать надлежащим образом, подвергать чистке, проверке и калибровке (о чем следует вести записи) для подтверждения того, что были обеспечены все контролируемые условия. Оборудование должно соответствовать государственным стандартам или требованиям GLP (ГОСТ 330442014).

Все вещества и реагенты следует маркировать надлежащим образом с указанием наименования, концентрации, срока годности и условий хранения. В соответствии с принципами $G L P$, касающимися тестируемых и стандартных объектов, должны быть соблюдены условия хранения и обращения с веществами для обеспечения их идентичности, стабильности, правильности подготовки доз для введения в тест-систему (Прин- ципы..., 2012). Для предотвращения загрязнения в испытательном центре должны быть отдельные помещения или зоны для получения и хранения испытуемых и стандартных (контрольных) объектов (ГОСТ 33044-2014).

Требования к содержанию животных. В обширном своде нормативных актов, составляющих системы GLP FDA и GLP OECD, можно выделить три основных документа, регламентирующих содержание животных и использование их в экспериментах:

- Guide for the Care and Use of Laboratory Animals: Eighth Edition, 2011 (Руководство по уходу и использованию лабораторных животных),

- Европейская Конвенция о защите позвоночных животных, используемых для экспериментов или в иных научных целях (Страсбург, 18 марта 1986 г.) ETS N 123 с пересмотренным Приложением А (2006) (для европейских стран, не входящих в ЕС),

- Directive of the European Parliament and of the Council of 22 September 2010 on the protection of animals used for scientific purposes, 2010/63/ EU (для европейских стран, входящих в ЕС) (Директива Европейского парламента и Совета от 22 сен'яябя 2010 г. о защите живо'ных, используемых для научных целей, 2010/63/EC).

Аккредитацию питомников и вивариев на соответствие требованиям этих документов проводит созданная в 1965 г. организация по аттестации и аккредитации содержания лабораторных животных (Association for Assessment and Accreditation of Laboratory Animal Care International, http://www.aaalac.org). Как следует из официального сайта этой организации, к 2016 г. аккредитовано более 950 компаний, университетов, научно-исследовательских институтов, больниц и других учреждений в 41 стране. Из них в США расположено 662, в Китае - 58, Японии - 26, Южной Корее - 19, во Франции - 19, в Индии 17 , на Тайване - 16 , в ФРГ - 15, Великобритании - 9. В России аккредитацию прошли только два учреждения: НПП «Питомник лабораторных животных» и собачий питомник, принадлежащие филиалу Института биоорганической химии РАН в г. Пущино.

Постоянно возрастают требования к качеству лабораторных животных. Ежедневный уход за животными (санитарная обработка помещения и оборудования, раздача кормов, смена подстилок) должен осуществлять квалифицированный персонал. Лабораторным животным в питомнике и вивариях должны быть обеспечены:

- полноценные кормление и уход;

- поддержание нормального состояния здороВья;

- содержание в соответствующих для каждого вида нормативных условиях; 
- возможность удовлетворения физиологических и поведенческих потребностей;

- ежедневный контроль условий содержания;

- быстрое устранение недостатков и факторов, могущих повлечь за собой стресс и страдания животных (Руководство..., 2010).

Прием животных в виварии производят из специализированных питомников, благополучных по инфекционным заболеваниям, при наличии на каждую партию животных ветеринарных свидетельств об отсутствии заболеваний, опасных для человека и животных (СП 2.2.1.3218-14). Все вновь поступившие в виварий животные должны быть осмотрены ветеринарным врачом и изолированы в помещения для карантина. Для мышей, крыс, хомяков, морских свинок карантинный период составляет 5-15 дней (Руководство..., 2010).

В течение всего года независимо от наружных погодных условий в помещениях для лабораторных животных необходимо поддерживать на требуемом уровне основные показатели микроклимата - температуру и влажность воздуха, кратность воздухообмена, давление и скорость движения воздуха, содержание в нем загрязняющих веществ, уровень шума, освещеннос'ть (ГОСТ 33044-2014). Поскольку в виварии Института биологии Коми НЦ УрО РАН предполагается и в дальнейшем содержать мышей, крыс и морских свинок, здесь мы приводим нормативы только для этих животных: температура воздуха $18-26{ }^{\circ} \mathrm{C}$, относительная влажность 30-70\%, кратность воздухообмена: вытяжка 8 объемов/ч, приток - 1015 объемов/ч. В помещениях содержания животных должно быть искусственное освещение - яркость до 325 лк на расстоянии 1 м от пола, рекомендуется чередовать световой режим - 12 ч свет/ 12 ч темнота, шум до 85 дБ (Руководство..., 1996, 2010). Особей одного вида необходимо содержать

Нормативы содержания животных в клетках (Руководство..., 1996)

\begin{tabular}{l|c|c|c}
\hline Животные & $\begin{array}{c}\text { Масса, } \\
\text { г }\end{array}$ & $\begin{array}{c}\text { Площадь } \\
\text { дна клетки } \\
\text { на одно } \\
\text { животное, см }\end{array}$ & $\begin{array}{c}\text { Высота, } \\
\text { см }\end{array}$ \\
\hline Мыши, полевки & $<10$ & 39 & 13 \\
& До 15 & 52 & 13 \\
& До 25 & 77 & 13 \\
Самка мыши с потомством & $>25$ & 97 & 13 \\
Крысы & $<100$ & 330 & 13 \\
& До 200 & 110 & 18 \\
& До 300 & 148 & 18 \\
До 400 & 258 & 18 \\
Самка крысы с потомством & До 500 & 387 & 18 \\
Морские свинки & $>500$ & 452 & 18 \\
& $<350$ & 800 & 18 \\
& $>350$ & 387 & 18 \\
& & 652 & 18
\end{tabular}

в отдельном помещении (в крайнем случае, на отдельных стеллажах) (Руководство..., 1996). При размещении животных необходимо строго соблюдать нормативы площади и высоты клетки (см. таблицу).

Полноценность корма, сбалансированность всех его компонентов является важнейшим условием, обеспечивающим здоровье животного, поддержание неспецифической резистентности его организма на высоком уровне. Корм для животных должен быть видоспецифичным, неконтаминированным, сбалансированным по питательному составу, не содержать токсичных агентов (ГОСТ-Р 50258-92). Гранулированный комбикорм следует хранить в сухих, чистых, хорошо проветриваемых, не зараженных амбарными вредителями и дикими грызунами складских помещениях, не имеющих посторонних запахов, при температуре $+5{ }^{\circ} \mathrm{C}$ и влажности 50-60\% (Руководство..., 2010). Обязателен свободный доступ животных к воде, которая может быть из водопровода (СанПиН 2.1.4.1074-01).

В качестве подстилки для крыс и мышей рекомендуется использовать опилки, стружки или мелкую щепу (длина 5-20 мм, толщина 1-2 мм) из экологически чис'ой древесины лиственных пород. Не допускается использовать подстилки из химически обработанной древесины, а также из древесины хвойных пород. Подстилку автоклавируют на поддонах при режиме $118{ }^{\circ} \mathrm{C}$ в течение 30 мин. Контактную подстилку в клетках, где содержатся крысы и мыши, меняют с периодичностью один раз в семь дней. Чистую подстилку рассыпают в клетки из расчета 0.5 л на $500 \mathrm{~cm}^{2}$ (Руководство..., 2010).

Утилизация отходов. Обработка и удаление отходов должны быть выполнены таким образом, чтобы не подвергать опасности животных и персонал при проведении исследований и не исказить их результаты. Для этого требуется обеспечить соответствующие условия для сбора, хранения и вывоза отходов, а также процедур их дезактивации и транспортировки (ФЗ № 89 от 24.06.1998; ГОСТ 33044-2014). Виварий должен быть обеспечен специальным оборудованием для дезинфекции клеток, инвентаря, а также условиями для сбора, хранения, удаления (утилизации) отходов и трупов животных (СП 2.2.1.3218-14).

Гуманное отношение к животным является основной целью принципов GLP. При планировании экспериментов на животных исследователь обязан руководствоваться принципами «трех $\mathrm{R}$ » (replacement - замена болезненных для животных әкспериментов опытами, не причиняющими страданий; reduction - уменьшение числа опытов с животными; refinement - улучшение методики с целью об- 
легчения страданий подопытных животных) (Руководство..., 2010). Комиссия по биоэтике может на основании СОП (стандартные операционные процедуры), выполняемых в лаборатории, контролировать и оценивать работу исследователей при проведении экспериментов. Все действия, которые могут причинить боль лабораторным животным (операции, тотальное обескровливание), проводят с использованием наркотизирующих средств. Если по условиям эксперимента противопоказано применение анестезии, то все вышеуказанные действия необходимо проводить в максимально короткий срок (Руководство..., 1996).

Стандартизация лабораторных животных. Получение надежных и воспроизводимых результатов экспериментов на лабораторных животных можно достигнуть лишь при соблюдении стандартности всех его слагаемых и условий проведения. В этом смысле лабораторное животное является наиболее уязвимым звеном в эксперименте (Каркищенко, 2005). Состояние лабораторного животного зависит от воздействия многочисленных экзогенных и эндогенных факторов, влияние которых не всегда бывает явным и регистрируемым. Среди них следует отметить, прежде всего, наследуемые особенности животных (генетические факторы), а также факторы биологической природы - вирусные, бактериальные инфекции и паразитические инвазии, которые могут не вызывать клинически явную картину заболевания. Поэтому для получения надежных и воспроизводимых результатов разработана стандартизация лабораторных животных по генетическому и микробиологическому статусу (Руководство..., 2010). Выбор животных определяется целью эксперимента. Так, при оценке токсикологического действия веществ, определения фармакологической активности удобно использовать конвекционных животных - чаще всего линейных (инбредных), для которых характерна генетическая однородность. Кроме того, в последнее время для производства вакцин, испытания новых фармакологических средств используют SPF (безмикробные) животных, для разведения и содержания которых требуется соблюдение более сложных условий (наличие барьерной системы).

В 1929 г. Кларенс Кук Литтл основал лабораторию, предназначенную для всестороннего изучения генетики мышей, которая сейчас известна как Джексоновская лаборатория (The Jackson Laboratory). Эта лаборатория является крупнейшим в мире поставщиком практически любых генетических ресурсов лабораторных животных. Среди других крупных и надежных поставщиков лабораторных животных следует отметить компании Taconic Farms, Harlan Sprague Dawley Inc., Charles River Laboratories. В России крупными поставщиками лабораторных животных надлежащего качества являются НПП «Питомник лаборатор- ных животных» (ИБХ РАН, г. Пущино), питомник в Новосибирском научном центре на базе ИЦиГ СО РАН, Федеральное государственное унитарное предприятие «Питомник лабораторных животных "РАППОЛОВО» и др. Известно более 25 тыс. линий и стоков только лабораторных мышей. Информацию об этих животных можно найти в Международном регистре линий мышей (International Mouse Strain Resource, www.findmice.org).

В эколого-биологических исследованиях, проводимых сотрудниками Института биологии Коми НЦ УрО РАН, используют животных (полевкиэкономки, рыжие полевки, пашенные полевки), отловленных в природных условиях. Следует отметить, что при работе с дикими животными необходимо выполнять ряд требований (СП 1.3.232208 и ГОСТ 31885-2012) и рекомендаций (Практическое..., 2004). Стандартизации по микробиологическому статусу данные животные не подлежат.

Требования к персоналу и организации экспериментов на лабораторных животных. Федерация европейских научных ассоциаций по лабораторным животным (FELASA) выделила че'ыре категории лиц, имеющих отношение к экспериментам на животных (которые не являются взаимоисключающими): категория А - лица, осуществляющие уход за животными; категория В лица, проводящие эксперименты на животных; категория C - лица, ответственные за руководство экспериментами на животных; категория D специалисты в области науки о лабораторных животных.

До начала каждого исследования должен быть разработан план в письменном виде (ГОСТ $33044-$ 2014). План должен содержать полную информацию об исследовании, испытуемом и стандартном образце, методах испытаний, обоснование выбора тест-системы, уровнях доз и/или концентраций, частоте и продолжительности введения образца и др. Все методы, процедуры, манипуляции, выполняемые сотрудниками в испытательном центре, должны быть описаны в письменных утвержденных руководством документах (COП), предназначенных для гарантии качества и полноты данных, полученных в процессе исследования. Персонал, занятый в экспериментах, должен знать и владеть СОП, необходимыми для работы. Все отклонения от СОП следует документировать и рассматривать их влияние на качество получаемых результатов. Неукоснительное соблюдение СОП помогает избежать ошибок, обучать персонал, корректировать существующую практику, ускорять процедуры, устанавливать правила документации получаемых данных (Принципы..., 2012). По окончании каждого исследования должен быть подготовлен заключительный отчет с полной информацией об исследовании. 
Согласно стандартам $G L P$, квалификация каждого сотрудника должна быть подтверждена документально. Должны быть четко определены обязанности и ответственность персонала, кроме того, необходимо проводить своевременное как внутреннее, так и внешнее повышение квалификации сотрудников. В ГОСТ 33044-2014 подробно описаны требования к руководителю испытательного центра, основной задачей которого является контроль и организация слаженной работы всех составляющих центра - от обеспечения потребности в помещениях, оборудовании и материалах до организации валидации и контроля архивных данных. Ключевое место в организации исследований по стандартам GLP принадлежит службе обеспечения качества. Специалисты этой службы не должны принимать участие в проверяемых ими исследованиях и иметь подготовку, специальные знания и опыт на уровне, необходимом для выполнения своих обязанностей, но должны быть знакомы с СОП. Круг обязанностей персонала по обеспечению качества широк (ГОСТ 33044-2014), главными задачами сотрудников этой службы являются проверки плана исследования и соответствия самого выполняемого исследования на всех его этанах шринципам GLP. Кроме того, специалисты службы оценивают доступность планов исследования и СОП персоналу, вовлеченному в проведение исследования, осуществляют различные инспекционные проверки в соответствии с графиком, который составляется аудитором после проверки плана исследования и ознакомления с расписанием процедур. Все документы службы обеспечения качества подлежат архивированию (Принципы..., 2012).

Для каждого конкретного эксперимента назначается руководитель, которым может быть научный сотрудник или иной специалист, имеющий необходимый уровень образования, соответствующую квалификацию и опыт работы. Руководитель исследования осуществляет общее руководство, несет персональную ответственность за выполнение испытания и итоговый отчет (Обязанности..., 2009). Перед началом исследования руководитель должен ознакомить с планом персонал и службу по обеспечению качества с целью оценки соответствия плана принципам $G L P$. Кроме того, руководитель несет ответственность за своевременное архивирование всех документов и материалов исследования (план, первичные материалы, отчеты) (ГОСТ 33044-2014).

Персонал, выполняющий исследование, должен знать и соблюдать требования правил GLP, план эксперимента и СОП, своевременно и точно вести сбор первичных данных и нести ответственность за достоверность представленной ими информации, соблюдать правила техники безопасности.
Ветеринарная помощь. В виварии в обязательном порядке должно быть предусмотрено оказание ветеринарной помощи (включая выходные и праздничные дни) и ежедневный осмотр животных (Руководство..., 2010).

В соответствии с требованиями $G L P$ в исследовательском центре необходимо наличие архива, в котором должны быть созданы все условия для безопасного и качественного хранения архивных материалов (планов исследования, первичных данные, СОП, заключительных отчетов и образцов, записи всех инспекций и т.д.) (ГОСТ 33044-2014). Ответственность за архив несет архивариус, который разрабатывает системы индексации, процедуры поиска, учета и выдачи архивных материалов.

Особое внимание следует обратить на процедуру прохождения инспекций, необходимых для получения и поддержания статуса соответствия принципам GLP. Национальные и межгосударственные стандарты по надлежащей лабораторной практике, гармонизированные с документами ОЕСР, подробно представлены в работе (Зайцева, 2014).

В заключение отметим, что, несомненно, внедрение в экспериментальные научные исследования принципов $G L P$, в частности, требований к обустройству вивариев, оборудованию, содержанию и гуманному обращению с животными, является важным и нужным на пути признания полученных данных, в том числе и на международном уровне. Однако при всей привлекательности $G L P$-лабораторий отрицательным моментом является то, что лаборатории, которые создаются в России, получаются очень дорогими и, соответственно, стоимость научных исследований, которые могут проводиться в таких лабораториях, существенно возрастает. При принятии единого решения об аккредитации лаборатории по стандартам GLP нужно учитывать конечную цель деятельности лаборатории. Если это доклинические исследования лекарственных средств, косметической продукции, ветеринарных препаратов, пищевых и кормовых добавок, а также химических веществ промышленного назначения с целью коммерческой реализации продукции, тогда соблюдение всех стандартов должно быть строго обязательным. В случае, когда в лаборатории проводится научно-исследовательская работа и часть экспериментов имеет «поисковый» характер (новые подходы, средства, методы, объекты), аккредитация по стандартам GLP не всегда должна быть обязательным условием.

\section{ЛИТЕРАТУРА}

ГОСТ 31885-2012. Принципы надлежащей лабораторной практики $(G L P)$. Применение Принципов $G L P$ к исследованиям в полевых условиях [Электронный ресурс]. - М. : Стандартинформ, 2013. - 
Режим доступа: http://standartgost.ru/g/ГОСТ 31885-2012.

ГОСТ 33044-2014. Принцины надлежащей лабораторной практики [Электронный ресурс]. - М. : Стандартинформ, 2015. - Режим доступа: http:// gostexpert.ru/gost/gost-33044-2014.

ГОСТ Р 50258-92. Комбикорма полнорационные для лабораторных животных. - Режим доступа: http://www.gostbaza.ru/?gost=28067.

ГОСТ Р 53434-2009. Принципы надлежащей лабораторной практики [Электронный ресурс]. - М. : Госстандарт России, 1994. - Режим доступа: http: //gostrf.com/normadata/1/4293824/4293824581.pdf.

Добротная лабораторная практика (GLP) - основа обеспечения качества доклинических исследований / О. Н. Хохлова, Т. Ю. Жармухамедова, Т. А. Гуськова, А. Н. Мурашев // Молекулярная медицина. - 2009. - № 5. - С. 42-47.

Каркищенко, Н. Н. Основы биомоделирования / Н. Н. Каркищенко. - М. : Изд-во ВПК, 2005. - 608 с. Курская, А. Кому с GLP жить хорошо / А. Курская // Фармацевтический Вестник. - 2014. - № 34 .

Мошкин, М. П. Постгеномная эра или зачем нужны 300 тысяч мышей / М. П. Мошкин // Наука из первых рук. - 2008. - № 4 (22). - С. 16-53.

Об отходах производства и потребления (Федеральный закон от 24 июня 1998 г. № 89-ФЗ [Электронный ресурс] // СПС «Консультант Плюс». Режим доступа: http://www.consultant.ru/document/cons_doc_LAW_19109/.

Обязанностй руководителя исследования при проведении испытаний безопасности химических веществ, биотехнологических и нанотехнологических продуктов в соответствии с правилами надлежащей лабораторной практики / Т. Ю. Жармухамедова, О. Н. Хохлова, Т. А. Гуськова, Д. И. Ржевский, А. Н. Мурашев // Токсикологический вестник. - 2009. - № 5. - С. 2-4.

Практическое руководство по биологической опасности в лабораторных условиях. Издание третье. - Женева : ВОЗ, 2004. - 190 с.

Принципы GLP - залог достоверности исследований / О. Н. Хохлова, Т. Ю. ЖЖармухамедова, Д. И. Ржевский, А. Н. Мурашев // Методы оценки соответствия. - 2012. - № 10. - С. 16-20.

Принципы надлежащей лабораторной практики: учебное пособие / Т. М. Зайцева, Е. Н. Веснина, О. В. Мезенцева, О. Ю. Чечеватова, М. А. Зайцева // Под научной ред. Д. О. Скобелева. - М. : АСМС, 2014. 99 c.

Руководство по лабораторным животным и альтернативным моделям в биомедицинских исследо- ваниях / Под ред. Н. Н. Каркищенко, С. В. Грачева. - М. : Профиль-2С, 2010. - 358 с.

Руководство но содержанию и использованию лабораторных животных. - USA : National Academy Press, Washington, D.C., 1996.

СанПиН 2.1.4.1074-01. Питьевая вода. Гигиенические требования к качеству воды централизованных систем питьевого водоснабжения. Контроль качества [Электронный ресурс]. - М., 2002. - Режим доступа: http://standartgost.ru/g/СанПиН 2.1.4.1074-01.

СанПиН 2.2.1/2.1.1.1278-03. Гигиенические требования к естественному, искусственному и совмещенному освещению жилых и общественных зданий [Электронный ресурс]. - М., 2003. - Режим доступа: http://gostrf.com/norma_data/11/11776/ index.htm.

CП 1.3.2322-08. Безопасность работы с микроорганизмами III-IV групп патогенности (опасности) и возбудителями паразитарных болезней. - Режим доступа: http://docs.cntd.ru/document/902091086.

СП 2.2.1.3218-14 от 29.08.2014 № 51. Санитарно-эпидемиологические требования к устройству, оборудованию и содержанию экспериментально-биологических клиник (вивариев) [Электронный ресурс]. - М., 2014. - Режим доступа: http://rospotrebnadzor.ru/documents/details.php?ELEMENT ID $=3521$.

Хамидулина, X. X. Требования GLP к вивариям / Х. Х. Хамидулина, А. Р. Егизарян, Д. А. Рабикова // Методы оценки соответствия. - 2012. № $10 .-$ C. 28-32.

AAALAC International, Международная ассоциация по оценке и аккредитации ухода за лабораторными животными. - Режим доступа: http:// www.aaalac.org.

Guidelines for Nomenclature of Genes, Genetic Markers, Alleles, and Mutations in Mouse and Rat. -

Режим доступа: http://www.informatics.jax.org/ mgihome/nomen/gene.shtml.

International Committee on Standardized Genetic Nomenclature for Mice. - Режим доступа: http:// www.informatics.jax.org.

International Mouse Strain Resource, IMSR. Режим доступа: http:// http://www.findmice.org/.

Murashev, A. N. Application of GLPs in Russia Federation for testing of anti-infections medical products. OECD / A. N. Murashev // Russia Federation workshop on «Biosecurity of microbial resources - complementing innovation». 20-21 September 2006. Moscow. - P. 20.

OECD Series on Principles of Good Laboratory Practice and Compliance Monitoring - № 1. ENV/ MC/CHEM(98)17. - Paris, 1998.

\title{
BASIC PRINCIPLES OF GOOD LABORATORY PRACTICE (GLP) IN THE REGENERATION OF THE VIVARIUM AND RESEARCH
}

\author{
O.V. Raskosha ${ }^{1,2}$, A.I. Kichigin ${ }^{1}$ \\ ${ }^{1}$ Institute of Biology of Komi Scientific Centre of the Ural Branch of the Russian Academy of Sciences, Syktyvkar \\ ${ }^{2}$ Syktyvkar State University named after P. Sorokin, Syktyvkar
}

Abstract. The article deals with the basic requirements of GLP (Good Laboratory Practice) to arrangement and design of vivariums, content of animals, as well as to organization of the test centers.

Key words: Principles of GLP, the requirements for the keeping of animals, improvement vivarium, test center, research 